\title{
Prolactin-Secreting Adenomas - Surgical Results
}

\author{
Giulio Maira, Carmelo Anile, Laura De Marinis and Antonino Barbarino
}

\begin{abstract}
The long-term follow-up of the transsphenoidal microsurgical treatment in 119 consecutively operated women with a PRL-secreting adenoma is presented. An apparent total removal of the tumor was achieved in 98 cases with an enclosed tumor ( 58 grade I and 40 grade II). In the remaining cases the removal was considered partial. The achievement of persistent normal PRL basal levels was verified in 61 patients (44 grade I and 17 grade II) who had an apparent total removal of the adenoma. In the 37 remaining patients who were thought at surgery to have had total removal we have distinguished two groups: 30 patients showed a "relapse" or "persistence" of PRL levels below $200 \mathrm{ng} / \mathrm{ml}$ without clinical and radiological signs of tumor regrowth, and 7 patients with a PRL level higher than $200 \mathrm{ng} / \mathrm{ml}$ who had evidence of PRL-secreting tumor recurrence.

RÉSUMÉ: Adénomes sécrétant de la prolactine : résultats chirurgicaux Dans ce travail, nous analysons le suivi à long terme du traitement microchirurgical transsphénoïdal chez 119 femmes consécutivement opérées pour un adénome à PRL. Une exérèse totale apparente a été réalisée dans 98 cas avec tumeur enclose (58 grades I, 40 grades II). Dans les autres cas, l'exérèse a été considérée comme partielle. L'obtention de valeurs de PRL de base normales a été vérifiée chez 61 patients (44 grades 1, 17 grades II) avec exérèse apparemment complète. Chez les 37 autres patients où nous étions convaincus d'une exérèse totale à la chirurgie, nous pouvons distinguer deux groupes: dans le premier, nous avons retrouvé 30 patients qui montraient une "rechute" ou "persistance" de valeurs élevées de PRL non-évolutives, inférieures à $200 \mathrm{ng} / \mathrm{ml}$ sans évidence clinique ou radiologique de récidive tumorale; dans le second groupe, il s'agissait de 7 patients avec taux de PRL supérieurs à $200 \mathrm{ng} / \mathrm{ml}$ et chez lesquels une récidive de la croissance de la tumeur à PRL a été démontrée.
\end{abstract}

Can. J. Neurol. Sci. 1990; 17:67-70

Transsphenoidal surgery is an effective treatment for patients with Prolactin (PRL) secreting adenomas. The tumor is often totally removed, PRL levels frequently return to normal and normal endocrine functions are restored. $1,2,3,4$

However, in some cases the surgical treatment is unable to normalize the PRL levels. Furthermore, even in patients with post-surgical normalization of PRL basal levels a late hyperprolactinemia can occur. $3.4,5,6.7,8$ This phenomenon may be due to disrupted pituitary-hypothalamic relationships or to the recurrence of the PRL-secreting tumor. Long term follow-up should permit a better assessment of these different possibilities.

\section{METHOdS AND MATERIALS}

From July 1976 to June 1985, 119 women underwent transsphenoidal removal of a PRL-secreting pituitary adenoma, diagnosed by hormonal data and radiological examinations (skull X-ray, CT-scan). Their age ranged from 14 to 62 years (mean age 28 years). Excluded were male patients and cases having previous surgery or radiation. The diagnosis was histologically verified using immuno-histochemical hormone staining. Forty-one cases had previously been treated with bromocriptine medication for at least one year. The reason for surgery was medication intolerance or a progressive increase of
PRL basal levels, when the drug treatment was interrupted. The anatomo-radiological alterations of the sella turcica were classified, according to Hardy and Vezina, ${ }^{9}$ as grade I in 59 patients, grade II in 48, grade III in 6 and grade IV in 6 (Figure I).

The presurgical basal PRL levels ranged from 50 to more than $8000 \mathrm{ng} / \mathrm{ml} ; 24$ patients had basal serum PRL levels below $101 \mathrm{ng} / \mathrm{ml}, 45$ from 101 to 250,22 from 251 to 500,12 from 501 to 1000 and 16 above 1000 (Figure 2). We analyzed: 1) PRL basal values (upper normal range $=20 \mathrm{ng} / \mathrm{ml}$ ); 2) PRL dynamics as evaluated on the basis of the PRL responses to the Thyrotropin Releasing Hormone (TRH, $200 \mathrm{mcg}$ i.v.) and to the antidopaminergic drug Metoclopramide (MCP, $10 \mathrm{mg}$ p.o.) as previously described. 10 The responses are defined as positive when at least a two fold increase of the PRL baseline value is reached. Note that all the patients before surgery showed an absent or blunted response of PRL to both TRH and MCP stimuli. 11 We have previously demonstrated that total removal of the adenomatous tissue can be followed by the reestablishment of normal responses of PRL to these stimuli, indicating a normalization of the hypothalamic-pituitary relationship;113) Other pituitary functions using standard procedures. 10 The modalities of sample collection and the radioimmunoassay (RIA) method used for hormone determinations were also reported pre- 


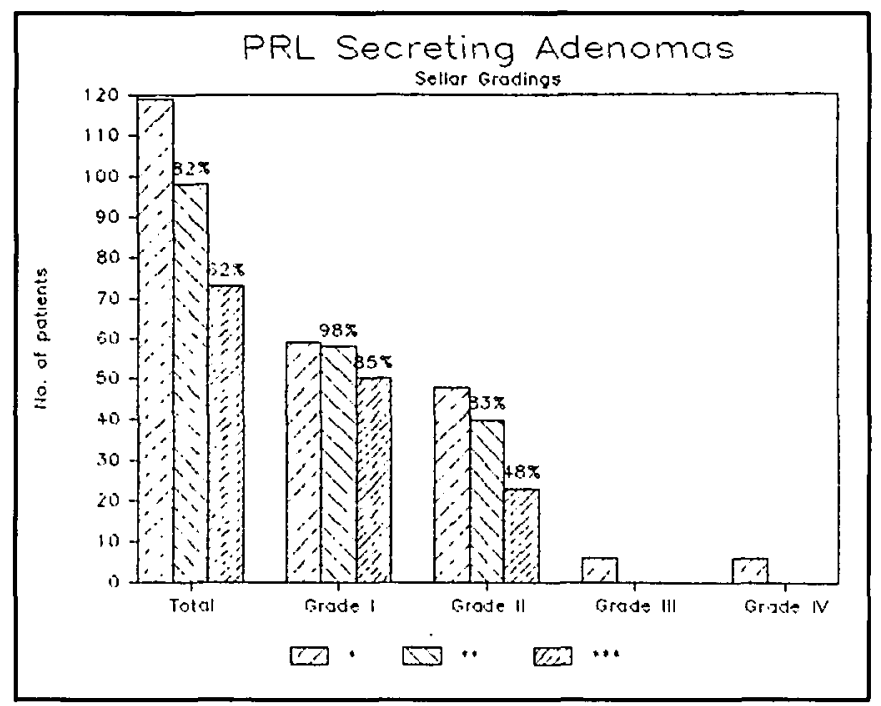

Figure I - Distribution by pre-surgical sellar classification; total cases $\left({ }^{*}\right)$, those with apparent total removal of the adenoma $\left({ }^{* *}\right)$ and with early post-surgical PRL level normalization (***).

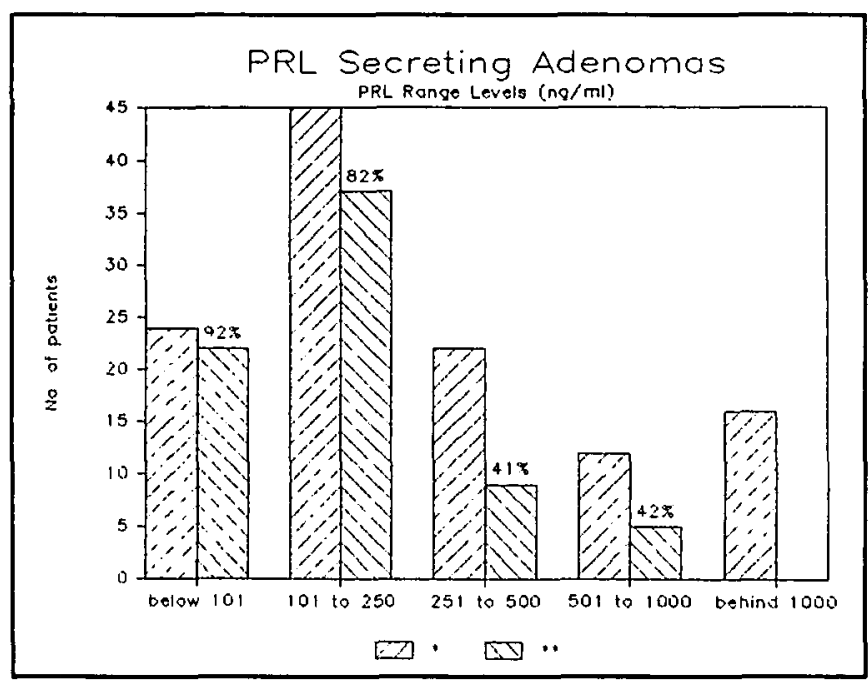

Figure 2 - Distribution by pre-surgical PRL levels; total cases (*) and those with early post-surgical PRL level normalization (**).

viously. 1,12 In addition, follow-up studies ranging from 1 to 9 years after surgery were carried out. In the majority of cases CTscan was performed a few months or years after the surgery. In some, contrast cisternography was done.

\section{Results}

\section{Surgical aspects (Figure 1)}

An apparent complete removal of the tumor was obtained at surgery in 98 cases $(82 \%)$. They belonged to grade I and II, 58 and 40 cases respectively. In $8 \%$ of the enclosed adenomas (1 case of grade I and 8 cases of grade II) complete removal was not achieved in some because of difficulty in differentiating between normal gland and tumor, bleeding from the cavernous sinus or local infiltration. In the remaining 12 cases, all grades III or IV, surgery failed to result in complete tumor removal.

\section{Hormonal aspects}

\section{Early results}

Normalization of PRL basal levels, with restoration of regular menses and the disappearance of galactorrhea, was obtained in $73(62 \%)$ of the total. All of these patients had a total removal. If we consider the sellar grading, this result was reached in $50 / 59(85 \%)$ with sellar grade I and in $23 / 48(48 \%)$ of grade II (Figure 1). Considering the pre-operative PRL basal levels, early cure was obtained in $22 / 24(92 \%)$ of the patients with PRL basal value below $101 \mathrm{ng} / \mathrm{ml}$, in $37 / 45(82 \%)$ with values between 101 and 250 , in $9 / 22(41 \%$ ) having 251 to 500 and $5 / 12(42 \%)$ between 501 and $1000 \mathrm{ng} / \mathrm{ml}$ (Figure 2).

The 73 patients with an immediate post-surgical normalization of the PRL basal levels were divided into two groups: 40 patients $(55 \%), 28$ grade I and 12 grade II had positive PRL responses after TRH and MCP administration, and 33 (45\%) patients, 22 grade I and 11 grade II, who continued immediately after surgery to show negative response to both stimuli in spite of normal basal PRL levels. Among the remaining 25 patients with an apparent total removal of an enclosed adenoma, 21 (7 grade I and 14 grade II) showed postoperative PRL basal levels between 21 and $200 \mathrm{ng} / \mathrm{ml}$ and 4 ( 1 grade $I$ and 3 grade II) remained higher than $200 \mathrm{ng} / \mathrm{ml}$. None of them had normal PRL responses to dynamic stimulations postoperatively.

All the patients with partial removal of the adenoma maintained high PRL levels without response to the provocative stimuli. The long-term follow-up of these patients will not be discussed. In all the patients, the other pituitary functions remained unchanged after surgery.

\section{Late results}

Of the 40 patients who showed an immediate post-surgical normalization of basal PRL levels and whose PRL responses to dynamic testing normalized, the long term effect of the transsphenoidal adenomectomy was persistently normal basal PRL levels and normal responses to dynamic tests in 35 . In the 5 remaining patients ( 2 grade $I$ and 3 grade II), after a period ranging from 2 to 8 years, a late increase of basal PRL levels ranging from 26 to 150 , associated with the disappearance of the response to TRH and MCP occurred. This "relapse" of hyper-

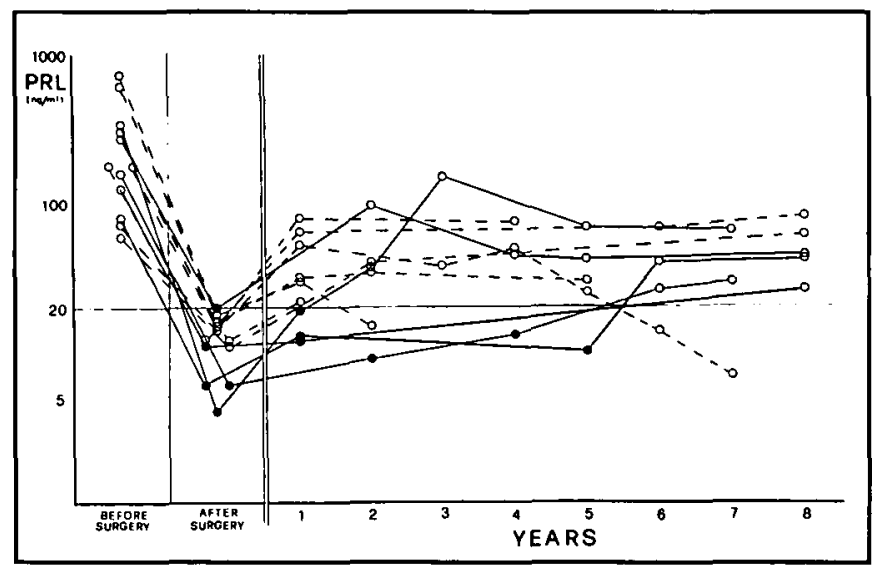

Figure 3 - Long-term follow-up of the 12 cases with a persistent or temporary relapse of hyperprolactinemia after early post-surgical $P R L$ normalization. Black circles $=$ positive response to $T R H$ and $M C P$ (see text). Empty circles $=$ negative response to $T R H$ and $M C P$ (see text). 
prolactinemia was followed by a stabilization without any further increase (Figure 3). In none of these patients could a recurrence of the adenoma be demonstrated.

Among the 33 cases with no early post-surgical response to stimulation, despite normal basal PRL levels, 15 ( 10 grade I and 5 grade II) subsequently achieved normal responses within a few months or years later. Ten of them ( 9 grade I and 1 grade II) had PRL values below $5 \mathrm{ng} / \mathrm{ml}$ in the immediate postoperative period. Four were below $10 \mathrm{ng} / \mathrm{ml}$ and one had a PRL value of $12 \mathrm{ng} / \mathrm{ml}$.

Seven patients ( 4 grade I and 3 grade II), who had postoperative $P R L$ values ranging from 11 to $18 \mathrm{ng} / \mathrm{ml}$, continued to have abnormal responses to the provocative tests and a progressive increase in the serum PRL concentration occurred, without detectable signs of tumor recurrence (Figure 3). Even in these cases the increase of PRL levels was always slight (no more than $80 \mathrm{ng} / \mathrm{ml}$ ) and followed by a stabilization. Furthermore, in 2 of them a spontaneous renormalization of basal PRL levels occurred some years later. The relapse of high PRL levels observed in these 7 patients was delayed by no more than one year in 6 of them.

The only woman in whom the hyperprolactinemia was detected after two years was pregnant twice following surgery and the PRL could not be checked before. The remaining 11 patients of this group continued to have normoprolactinemia with absent responses to the tests. Of the 21 patients with postoperative PRL levels between 21 and $200 \mathrm{ng} / \mathrm{ml}, 3$ ( 1 grade I and 2 grade II) showed a progressive increase of PRL above $200 \mathrm{ng} / \mathrm{ml}$ and radiological signs of tumor recurrence. All the other cases remained unchanged. Many of these were pharmacologically treated by dopaminergic drugs. The 4 patients with apparent total removal of the adenoma and postoperative PRL levels higher than $200 \mathrm{ng} / \mathrm{ml}$ remained hyperprolactinemic and were pharmacologically treated.

\section{Discussion}

The aim of surgical treatment in patients with a PRLsecreting adenoma is the complete removal of the tumor with sparing of the normal pituitary gland. This ideal result was obtained in $98(82 \%)$ of 119 women operated on by us. All the adenomas in which this was possible were grade I and II ("enclosed"). Nevertheless in 9 out of 107 (8\%) of the enclosed adenomas this result could not be achieved. Early postoperative normalization of basal PRL levels is proof of an adequate removal of the adenoma. However, not in every case in which the removal of the adenoma has been considered to be total did the PRL levels return to normal. In our experience, this happened in $73(62 \%)$ patients. The return to normal of the basal PRL levels immediately after the treatment does not necessarily imply that a permanent cure from the PRL-secreting adenoma is obtained. Longterm follow-up studies $3,4,5,6,7,8$ have demonstrated that a relapse of the hyperprolactinemia or a recurrence of the adenoma can occur. This raises serious questions ${ }^{13}$ about the optimum treatment of these tumors.

In order to clarify whether patients with postoperative normalization of basal PRL levels may still develop late hyperprolactinemia or a recurrence of the adenoma, we repeated the hormonal studies at different intervals after surgery. The reappearance of these responses seems to indicate not only the complete removal of the adenomatous tissue but also the reestablishment of normal pituitary-hypothalamic relationships. ${ }^{1}$ In none of these cases could a recurrence of the adenoma be demonstrated.6,8,13

Some normoprolactinemic patients showed an early post-surgical negative response to the stimuli. It seems that an absent or blunted response to the same tests is always observed in patients harboring a PRL adenoma. The lack of response in some of our patients raises the question that a small amount of residual adenoma left in the sella might cause this defect of pituitary function.

The long term follow-up study showed that some normoprolactinemic patients normalized their response to the tests within a few months or some years later. The majority of them had very low PRL levels after surgery. Our previous studies on the pre and postoperative DA tone in PRL secreting adenomas 12 strongly suggest that the normal pituitary lactotropes are functionally inhibited by an high DA tone before surgery and can remain atrophic and unresponsive to exogenous stimuli for some time after surgery. In none of the 33 cases with early normoprolactinemia was there hormonal or neuroradiological signs of recurrence. The data suggest that the reappearance of PRL response to the tests does not absolutely insure against a recurrent high prolactinemia nor does the absence of this response identify the patients who will relapse, even although the relapse rate was $21 \%$ in the absent response group compared to $12 \%$ in the responders.

In conclusion, an early normalization of basal PRL values, independent of normalization or not of the dynamic tests, is proof of a complete removal of a PRL-secreting adenoma.

Nevertheless, this does not exclude the possibility of subsequent functional hyperprolactinemia due to the appearance of some condition not present immediately after surgery. The most frequent pathological condition observed in these patients was a delayed post-surgical "empty sella" that might have caused the rise of the PRL levels. Also, in theory, a few remaining adenomatous cells can coexist with normal basal PRL values. Among all the cases of relapse of hyperprolactinemia reported in the literature, only one case described by Schlechte et al ${ }^{7}$ showed radiological evidence of tumor recurrence with PRL levels up to $1,000 \mathrm{ng}$.

Of the 25 patients with an apparent total removal of the tumor but persistent high postoperative PRL values, some soon presented radiological signs of residual tumor. This suggests that the removal of the adenoma was extensive but incomplete or, alternatively, that a disorder of the hypothalamic-pituitary functions was pre-existing or consequent to the surgery. Both these hypotheses appear to be possible. A few cases showed a progressive increase of hormonal level with radiological evidence of tumor. The majority had absence of further increase of PRL levels and of radiological signs of adenoma which supports the second possibility. The higher incidence of persistence of high PRL levels among patients with huge tumors suggests that the prolonged compression of the pituitary stalk can cause this persistent and stationary hyperprolactinemia, which has been found in patients suffering from different pathologies of the sellar region. ${ }^{4.14,15,16}$ Even in these cases, the possibility that hyperprolactinemia is due to non proliferating tumoral cells left during surgery, cannot be completely excluded. 
Table 1: PRL-Secreting Adenomas Long-term Results (apparent total removal)

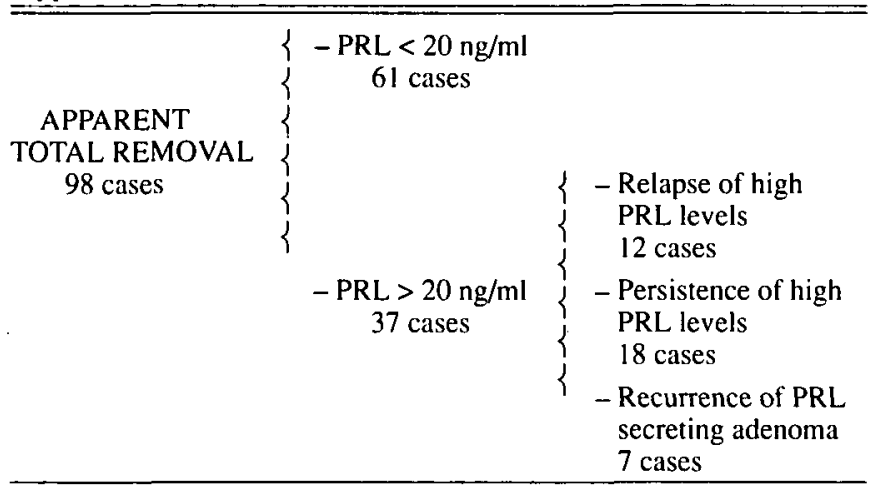

Among the 98 patients in whom an apparent total removal was carried out in 37 cases a complete endocrine cure was not obtained. Two sub-groups of such patients can be distinguished. To the first one belong the patients that presented a persistent or temporary relapse of high prolactinemia after a transitory postoperative normalization and the cases in whom we documented a postoperative reduction of PRL levels without a complete normalization, the absence of further increase of the hormonal values and no CT-scan evidence of tumor. To the second group belong cases in whom, at follow-up, hormonal and radiological signs indicated a persistence of adenomatous cells in spite of a surgical conviction that a complete removal was carried out.

All the patients with a postoperative hyperprolactinemia can be treated with dopaminergic drugs, but in only a few cases with signs of tumor regrowth or an obvious partial removal is there a possible indication for a radiotherapeutic treatment.

\section{REFERENCES}

1. Barbarino A, De Marinis L, Menini E, et al. Prolactin-secreting pituitary adenomas: prolactin dynamics before and after transsphenoidal surgery. Acta Endocrinol 1979; $91: 397-409$.

2. Jaquet P, Grisoli M, Guibout M, et al. Prolactin secreting tumors. Endocrine status before and after surgery in 33 women. J Clin Endocrinol Metab 1978; 46: 459-466.
3. Hardy J. Transsphenoidal microsurgery of prolactinomas: report on 355 cases. In: Tolis G, et al, eds. Prolactin and Prolactinomas. New York: Raven Press 1983; 431-440.

4. Maira G, Rossi GF, Anile C, et al. Prolactinomas: surgical results in 96 cases. In: Auer LM, Leb G, Tscherne G, Urdl W, Walter GF, eds. Prolactinomas. Berlin-New York: Walter de Gruyter 1985; 225-230.

5. Giovanelli M, Gaini S, Tomei G, et al. Follow-up review of microprolactinomas operated in 48 female patients. Excerpta Med Int Congr Ser 1982; 584: 189-196.

6. Rodman EF, Molitch ME, Post KD, et al. Long-term follow-up of transsphenoidal selective adenomectomy for prolactinomas. JAMA 1984; 252: 921-924.

7. Schlechte JA, Sherman BM, Chapler FK, et al. Long-term followup of women with surgical treated prolactin-secreting pituitary tumors. J Clin Endocrinol Metab 1986; 62: 1296-1301.

8. Serri $\mathrm{O}$, Rasio E, Beauregard $\mathrm{H}$, et al. Recurrence of hyperprolactinemia after selective transsphenoidal adenomectomy in women with prolactinoma. N Engl J Med 1983; 309: 280-283.

9. Hardy J, Vezina JL. Transsphenoidal neurosurgery of intracranial neoplasm. In: Thompson RA, Green JR, eds. Advances in Neurology. New York: Raven Press 1976; 261-264.

10. Barbarino A, De Marinis L, Anile C, et al. Dopaminergic mechanisms regulating prolactin secretion in patients with prolactinsecreting pituitary adenoma. Long-term studies after selective transsphenoidal surgery. Metabolism 1982; 31: 1100-1104.

11. Barbarino A, De Marinis L, Menini E, et al. Pre- and postoperative pituitary function tests in patients with prolactin-secreting pituitary adenoma. In: Camanni F, Müller EE, eds. Pituitary Hyperfunction: Physiopathology and Clinical Aspects. New York: Raven Press 1984; 333-342.

12. De Marinis L, Mancini A, Maira G, et al. Postoperative evaluation of dopaminergic tone in prolactinoma patients. II. Plasma thyrotropin response to metoclopramide. J Clin Endocrinol Metab 1984; 58: 405-409.

13. Tucker HStG, Grubb SR, Wigand JP, et al. Galactorrhea-amenorrhea syndrome: follow-up of forty-five patients after pituitary tumor removal. Ann Intern Med 1981; 94: 302-307.

14. Barbarino A, De Marinis L, Mancini A, et al. Prolactin dynamics in patients with non-secreting tumors of the hypothalamic-pituitary region. Acta Endocrinol 1985; 110: 10-16.

15. Maira G, Di Rocco C, Anile C, et al. Hyperprolactinemia as the first symptom of craniopharyngioma. Child's Brain 1982; 9: 205-210.

16. Maira G, Anile C, Roselli R, et al. Tableau anatomo-chirurgical et troubles endocriniens dans la pathologie diencéphalohypophysaire. Aggressologie 1986; 27: 217-219. 